INTERNATIONAL JOURNAL OF
ORGANIZATIONAL LEADERSHIP
ORGANIZATIONAL
LEADERSHIP

\title{
The Mediating Effect of Perceived Stress on Transformational and Passive-Avoidant, Leadership-Commitment Linkages
}

\author{
Ozge Tayfur Ekmekci ${ }^{*}$, Selin Metin Camgoz ${ }^{2}$, Semra Guney $^{3}$, Mustafa Kemal Oktem ${ }^{4}$ \\ ${ }^{1,2,3}$ Hacettepe University, Faculty of Economics and Administrative Science, Department of Business \\ Administration, 06532, Ankara- Turkey \\ ${ }^{4}$ Hacettepe University, Faculty of Economics and Administrative Science, Department of Political Science \\ and Public Administration, 06532, Ankara- Turkey
}

\section{Keywords: \\ Transformational leadership, Passive-avoidant leadership, Commitment, Stress}

\section{Received}

13 September 2021

Received in revised form

02 October 2021

Accepted

06 October 2021

*Correspondence:

otayfur@hacettepe.edu.tr

\begin{abstract}
The current study tests an integrative model that considers the plausible effects of transformational and passive-avoidant leadership styles on employees' affective, normative, and continuance commitment to the organization. While leadership styles are treated as predictors of commitment, perceived stress is treated as a mediating factor in understanding the underlying mechanism of commitment. Data were collected from 232 white and blue-collar employees working at regional divisions of a privatized organization, monitoring Turkey's electricity distribution services. The hypothesized mediation model was tested using structural equation modeling. Using the bootstrapping method, the indirect effects of both transformational leadership and passive-avoidant leadership on affective and normative commitment via perceived stress were found to be significant. However, contrary to the expectations, the mediating effects of perceived stress were found to be insignificant for relations between transformational leadership and continuance commitment and between passive-avoidant leadership and continuance commitment. The overall results suggest that employees tend to feel less tension and stress and thus ultimately become more affectively and normatively committed to the organizations when the supervisors exhibit transformational leadership behaviors. Passive-avoidant leadership behaviors, on the other hand, act as distal predictors of affective and normative commitment via perceived stress. By enacting passively and showing ignorance to subordinates' needs, passive leaders seem to intensify workplace stressors for followers.
\end{abstract}

Much has been said about the importance of leadership and what leadership is or should be. The abundance of empirical research examined the linkage between leadership and various 
outcomes such as employee well-being (Arnold, 2017; Liu, Siu, \& Shi, 2010), organizational citizenship (Nguni, Sleegers, \& Denessen, 2006), and commitment (Korek, Felfe, \& Zaepernick-Rothe, 2010). Nevertheless, studies examining the role of intervening or mediating variables on the relationship between leadership and the aforementioned outcomes are relatively scarce (Aydogmus et al., 2018). In other words, the positive or negative effects of leadership are well known, yet how a particular leadership style transmits its effects on subordinates is not that clear, thereby needs further elaboration (Korek et al., 2010). This research aims to investigate the mediating effect of subordinates' perceived stress on the linkage among two prominent leadership styles, namely transformational and passive-avoidant leadership, and organizational commitment (i.e., affective, normative, continuance commitment). Reflecting the constructive form, transformational leadership refers to behaviors of a leader that increase the followers' morale by inspiring vision, providing intellectual stimulation, and acting as a strong role model. In the unconstructive form, passive-avoidant leadership involves showing laissez-faire behaviors and providing insufficient guidance to followers (Bass \& Avolio, 1997). In terms of the outcome variable, organizational commitment mainly involves employees' attachment and identification with the organization and includes feelings of commitment and obligation to stay in the organization (Allen \& Meyer, 1990). The exploration of the associations among those variables could contribute to the extant literature by uncovering the mechanism through how leadership exerts its influence on the organizational commitment of subordinates and provides important insights to managers about the mechanism regarding how to mitigate the perceived stress level of the subordinates through leadership practices, and in turn, increases employees' attachment to the organizations.

Adhering to Bass and Avolio's (1995) leadership theory, the current study could contribute to the literature by exploring the impact of effective and ineffective leadership styles on subordinates' perceived stress and commitment to the organizations. Drawing on Bass and Avolio's (1995) conceptualization, transformational leaders are regarded as active and effective by transforming subordinates' needs, aspirations, and priorities and motivating them to perform beyond expectations. Such leaders are assumed to reduce the perceived stress and tension of the subordinates, contributing to organizational commitment. Despite the huge number of studies addressing the role of transformational leadership on commitment (Korek et al., 2010; Walumbwa et al., 2005), there seems to be a gap in exploring the psychological mechanism of how leadership practices might influence the organizational commitment levels of the subordinates. Besides, a limited amount of research addressed whether active, inspiring, and motivating leadership as described in transformation leadership reduced the stress levels of subordinates (Nielsen et al., 2008).

Given the positive connotation of the leadership concept in minds, scholars have focused mostly on the positive effects (Judge \& Piccolo, 2004) by giving reference to servant, charismatic, or transformational leadership. However, given the recent corporate scandals and bankruptcies, researchers have shifted the focus to dysfunctional leadership, mostly abusive supervision, which comprises of "hostile verbal and non-verbal behaviors" displayed by managers and administrators (Tepper, 2000, p.178). Nonetheless, several researchers (e.g., Hinkin \& Schriesheim, 2008; Skogstad et al., 2007) highlighted that conceptualizing dysfunctional leadership only with active behaviors could be misleading. By being inadequate in responding and guiding the demands of the employees for completing the job demands (Che 
et al., 2017), passive-avoidant leaders can be regarded as harmful as destructive/abusive leaders. Indeed, some studies reported that passive leadership adversely affects the well-being of subordinates by increasing injuries in a work setting (Kelloway, Mullen, \& Francis, 2006) and creating psychological distress (Skogstad et al., 2007). Even though passive leadership may be more prevalent in organizations than positive leadership and destructive leadership (Aasland et al., 2010), Holtz and $\mathrm{Hu}$ (2017) indicated that noted extant literature regarding passive leadership is still weak and inconclusive in terms of depth and breadth, thus warrants attention. Hence, the current study offers important insights into the literature by revealing the plausible effects of passive-avoidant leadership on subordinates' perceived stress and organizational commitment. Thus, the study integrates theoretical perspectives and frameworks from the leadership, stress, and commitment literature to hypothesize that transformational and passiveavoidant leadership styles might, directly and indirectly, affect subordinates' commitment to the organizations.

\section{Theoretical Background and Hypotheses}

\section{Organizational Commitment Dimensions and Leadership Styles}

Mowday, Porter, and Steers (1982) describe commitment as "the relative strength of an individual's identification with and involvement in a particular organization" (p. 27). Commitment is regarded as a psychological process of employee-organization relationship concerning the decisions of employees to remain or leave their organization (Meyer \& Allen, 1991), and the three-component model of Allen and Meyer (1990) is taken into account to acknowledge the multidimensional side of the commitment construct. In the three-component model of commitment, the first component, affective commitment, refers to "one's emotional attachment, involvement, and identification with the organization" (Meyer \& Allen, 1991; p. 67). Accordingly, employees with affective commitment remain to work for the same organization as they are affectively connected to their organization and appreciate being part of it (Allen \& Meyer, 1990). The second component- normative commitment, refers to "a feeling of obligation toward organization" (Jaros, 1997, p. 320). The third component, continuance commitment, involves employees' remaining in the organization because of the perceived social or economic cost of leaving that organization (Meyer, Allen, \& Smith, 1993). Meyer, Allen, and Smith (1993) suggested that researchers treat commitment as a multidimensional construct because the authors argue that psychological states are different for each commitment dimension.

Previous research proposed that organizational commitment has several individual and organizational predictors. Leadership is argued to be one of the factors affecting followers' reactions to the organizations in the forms of commitment. Among the different leadership styles cited in the literature, the evidence for the effect of passive-avoidant leadership on commitment is relatively scarce as most leadership studies have focused on constructive leadership styles. In those studies, transformational leadership was found to positively relate to organizational commitment in different settings and cultures (e.g., Bono \& Judge, 2003; Nguni et al., 2006), predominantly in Western societies. Therefore, it seems worthwhile to explore the manifestations of different leadership styles on work outcomes in different societies and contextual backgrounds. 
Given the contextual nature of leadership practices, most managers in Turkey prefer to follow authoritarian and paternalistic leadership styles, which are seen as peculiar to Eastern cultures (Aycan et al., 2000). Nonetheless, it is also noted that the leadership ideals of employees seem to diverge from the prevalent leadership styles in Turkish organizations. For instance, Aycan and Fikret-Pasa's (2003) study revealed that employees prefer transformational leadership over authoritarian and paternalistic leadership styles. That preference was attributed to the contribution of transformational leadership practices into professional development, societal change, and advancement. With a similar token, it seems reasonable to expect leadership ideals to be compatible with transformational leadership given the fact that feminine and relatively collectivist Turkish culture (Hofstede, 1980) supports the benevolence, consensus, morality, consideration, which constitute the key dimensions of transformational leadership. Therefore, the current study addresses transformational and passive-avoidant leadership as examples of effective and ineffective leadership styles. Such an understanding is critical to comprehend the nature of the leader-follower relationships, organizational commitment, and followers' attitudes and behaviors.

\section{Transformational Leadership and Commitment}

It is intuitively appealing to expect transformational leaders to positively influence employees' commitment to the organization. Such leaders show consideration to followers' needs and provide opportunities for decision-making and inspiration. The intuition could be theoretically supported by Value Congruence Theory and the Norm of Reciprocity. According to Chatman (as cited in Bao, Dolan, \& Tzafrir, 2012, p.5), value congruence reflects a congruence of the work values of the person and others (i.e., supervisors, coworkers, workgroup, and the entire organization). By acting as role models, the transformational leader could shape employees' values to make them compatible with organizational values and motivate the employees toward organizational vision requiring extra-role performance and behaviors (Howell \& Avolio, 1993; Kuhnert \& Lewis, 1987). As time passes, the work values of the leader, organization, and subordinates/followers become similar. In such a situation, employees could feel the harmony between inner beliefs and the environment, thus experiencing lower levels of cognitive dissonance (Elliot \& Devine, 1994). The reduction of cognitive dissonance leads to positive attitudes toward the organization and internalization of organizational values, policies, and culture, thus fostering employees' commitment to the organization (Bao et al., 2012). The findings of Boxx, Odom, and Dunn (1991) supported the argument by showing the positive effect of value congruence between employee and organization on work outcomes, including job satisfaction and organizational commitment. Hence, transformational leaders could enhance value congruence by acting as role models and motivating employees in attaining organizational goals, which in the long run might increase the followers' attachment and commitment to the organization.

The norm of reciprocity might also serve as a possible justification for the aforementioned relationship. The norm of reciprocity refers to "a set of socially accepted rules regarding a transaction in which a party extending a resource to another party obligates the latter to return the favour" (Wu et al., 2006, p. 378). By showing concern for the comfort and welfare of the employees, transformational leaders could evoke a positive norm of reciprocity in which employees feel indebted to the leaders. Such feelings could foster organizational commitment 
by creating a desire for maintaining organizational membership and increasing the effort exerted for the best interests of the organization and the approval of organizational goals.

Considering the premises of value congruence, transformational leadership is expected to positively associate with affective commitment (Bycio, Hackett, \& Allen, 1995) by fostering intense feelings of emotional attachment. Indeed, the findings of a meta-analytic study showed transformational leadership to be positively associated with affective commitment (Meyer, Stanley, Herscovitch, \& Topolnytsky, 2002). However, as leaders play a role in socializing their subordinates, one might expect that transformational leaders might inspire their followers' sense of duty to remain committed to the organizations. Thus, transformational leaders acting as socialization agents could evoke the feeling of normative commitment. Indeed, Bycio et al. (1995) reported a weak yet positive association between transformational leadership and normative commitment. Therefore, building on the premises of value congruence and norm of reciprocity, we presume that transformational will positively predict affective commitment (Hypothesis 1. a), normative commitment (Hypothesis 1. b), and continuance commitment (Hypothesis 1. c) of followers.

\section{Passive-avoidant Leadership and Commitment}

Though providing employees guidance and structure to complete the work is an indispensable part of leadership, many leaders, if not all, seem to fail regarding the issue. Realizing the notion, researchers started to focus on what constitutes ineffective leadership. Although different conceptualization of ineffective leadership is important in its own right, the model of Bass and Avolio (1997) seems to provide a comprehensive picture regarding ineffective and effective leadership. According to the theory, passive-avoidant leadership consists of laissez-faire and passive management-by-exception dimensions (Bass \& Avolio, 1993; Kelloway et al., 2005). Individuals following the laissez-faire leadership style refrain from assuming accountability or discretion in making decisions; whereas individuals using passive management-by-exception tactics "only interfere with employees' actions once problems are observed and when disregarding those problems is impossible" (Bass \& Avolio, 1997; Che, Zhou, Kessler \& Spector, 2017, p. 340). Empirical evidence (e.g., Antonakis, 2001; Harold \& Holtz, 2015) suggests that laissez-faire and passive management-by-exception dimensions are correlated and represent a higher-order factor, labeled as passive-avoidant leadership.

Passive leaders are argued to give damage to the organizations because such leaders lack leadership skills (Kelloway et al., 2005) in making decisions, structuring the work, and motivating the employees, and they do not provide timely and adequate feedback that subordinates need to complete the assigned work (Bass \& Avolio, 1997). However, to date, only a few studies have addressed the relationship between passive-avoidant leadership and organizational commitment. In particular, Emery and Barker (1997) only examined the effect of management by exception component of passive-avoidant leadership on organizational commitment and reported a negative relationship between the variables.

The plausible association between passive-avoidant theory and organizational commitment could be explained with the Spill-over Effect and Psychological Contract concepts. Burris, Detert, and Chiaburu (2008) argue that adverse feelings toward the leader could also extend and transform into the negative feelings that are directed towards the organization. This argument seems reasonable given that employees tend to regard their supervisors as the 
agents/deputies of their organization, which in turn, display and feel negative feelings toward their organization (Tosunoglu \& Ekmekci, 2016). Moreover, employees working with unwanted, ineffectual, or disparaging supervisors might feel that the leaders may not protect them if needed (Schyns \& Schilling, 2013). Gradually, such negative feelings and expectations about the supervisor could erode the commitment to the organization.

Besides Spill-over Effect, Rousseau's (1989) psychological contract theory might work as a base for passive-avoidant leadership and commitment association. The psychological contract reflects "an individual's beliefs about the terms and conditions of a reciprocal exchange agreement between that person and another party" (Rousseau, 1989, p. 123). Accordingly, when employees believe their organizations or supervisors are unable to fulfill their promises and meet their obligations, they could perceive a psychological contract breach (Rousseau, as cited in Robinson, 1996) that might erode their commitment to the organizations. According to Robinson (1996), when employees realize a discrepancy between their supervisors' words and actions, they suspect about supervisor's integrity and lose confidence in such a way that their contributions will be appreciated and remunerated by the organization in the future. In this sense, passive-avoidant leaders or managers, who do not provide enough assistance and show concern for employees, could be regarded as inconsistent and dishonest by the employees. Furthermore, these feelings and beliefs could adversely affect interpersonal relations by casting doubts about the perceived benevolence of supervisors or management (Tosunoglu \& Ekmekci, 2016). Thus, passive-avoidant leaders could cause psychological contract breaches between employees and organizations, which might diminish the desire in being devoted to the organization either emotionally or normatively. Following this corollary, we hypothesize that passive-avoidant leadership will negatively predict affective commitment (Hypothesis 2. a), normative commitment (Hypothesis 2. b), and continuance commitment (Hypothesis 2. c) of followers.

\section{Leadership Styles and Perceived Stress}

Hobfoll's (1989), Conservation of Resources theory (COR), a prominent theory explaining the relationship between stressors and strains, proposes that individuals struggle to attain and maintain resources in both work and family lives. Indeed, the resources could be anything such as objects, conditions, personal characteristics, and valuable energy. According to the COR theory, individuals could experience stress and tension when faced with resource losses without resource gains (Hobfoll, 1989). In particular, transformational leaders could alleviate the stress and tension experienced by the followers by providing important resources such as guidance, timely feedback, and instrumental support. Supporting the notion, prior studies demonstrated that transformational leadership was negatively related to perceived stress (e.g., Amirkhani \& Kazemi, 2016) and positively related to employee well-being (Nielsen et al., 2008). Considering the premises of COR theory, it is expected that transformational leadership will negatively predict perceived stress (Hypothesis 3)

As in transformational leadership, COR theory could serve to describe the relationship between passive leadership and perceived stress. Passive leaders could act as workplace stressors as they cannot offer or deliver the necessary resources needed by their subordinates (Kelloway et al., 2005). In such a situation, subordinates may perceive resource "inadequacy 
or the threat of not obtaining necessary resources, which could result in heightened levels of stress" (Che et al., 2017, p. 340).

Besides COR theory, Kelloway et al.'s (2005) "root cause" framework of poor leadership could also provide explanations about the association between passive leadership and stress. The framework asserts that abusive and passive leadership can influence employees' health and well-being by shaping the existence and intensity of occupational stressors (Che et al., 2017). Particularly, passive leaders could increase employees' workload and cause delays in the work schedule. They tend to refrain from making timely decisions and only get involved with the problems when they occur (Kelloway et al., 2005). Moreover, by not providing adequate resources and detailed job descriptions, passive leaders could cause subordinates to do unnecessary tasks or spend extra time and energy to figure out their job duties. Passive leaders could also result in repeating the same activities/duties or even the same mistakes by failing to provide clear instructions or adequate feedback (Che et al., 2017). In short, the root cause framework of poor leadership asserts that ignorant leaders could accelerate the perceived role ambiguity, workload, and work pace, thus damaging employees. In line with this assertion, previous studies revealed that passive leadership increases employees' perceived stress through its influence on role stressors (e.g., Skogstad et al., 2007). In a recent study, Che et al. (2017) reported that passive leadership indirectly affected burnout by affecting workload and workfamily conflict.

As indicated before, the COR theory (Hobfoll, 1989) and the "root cause" framework (Kelloway et al., 2005) could offer a theoretical framework for explaining the impact of passive leadership on perceived stress. Considering the results of previous studies demonstrating the relationship between passive leadership and psychological outcomes such as psychological distress (Skogstad et al., 2007) and fatigue (Barling \& Frone, 2017), it is proposed that passiveavoidant leadership would relate to higher levels of perceived stress (Hypothesis 4).

\section{Perceived Stress and Organizational Commitment}

It is reasonable to expect stress to negatively predict employees' commitment to the organization since commitment is a psychological process. Without referring to the specific dimensions of commitment, Mathieu and Zajac (1990) investigated the association between stress and organizational commitment and reported moderately negative correlations in a comprehensive meta-analysis. Likewise, Jamal (1990) reported a negative association between perceived job stress and employee commitment to the organization using data gathered from nurses in Canada.

In the extant literature, stress is widely accepted as a predictor of commitment. However, as Mathieu and Zajac (1990) argued, high levels of organizational commitment might result in higher levels of stress in some instances as well. For instance, employees who are committed and attached to their organization might feel more stress and anxiety after an unexpected crisis. Acknowledging the possibility of reciprocal relations, the study assumes stress to be a predictor of commitment. The assumption is based on the "Spillover effect", which is explained in detail in the preceding sections. It is believed that negative feelings and experiences arising from perceived job stress could transform into feelings toward the organization, thereby hampering employees' commitment. Thus, it is expected that perceived stress will negatively predict 
affective commitment (Hypothesis 5. a), normative commitment (Hypothesis 5. b), and continuance commitment (Hypothesis 5. c).

\section{The Mediating Role of Perceived Stress}

The current study presumes leadership styles to act as distal workplace factors, which are believed to affect employees' stress levels and serve as a proximal predictor of employees' commitment to the organizations. Lowe, Kroeck, and Sivasubramaniam (1996) noted that transformational leaders transform the aspirations, needs, and values of subordinates in such a way that the followers can reach their full potential and complete the work as specified. Furthermore, by giving guidance and timely feedback, transformational leaders provide important resources to the followers and help the followers to protect the existing resources such as time and energy. Incongruent with COR theory premises, when individuals can gain and protect the resources they need, they experience less stress even though demands are high. Following the corollary, the study proposes that transformational leaders are likely to lessen employees' perceived stress. Then those mitigated levels of stress could be reciprocated by employees as being more committed to the organization. Hence, we presume that perceived stress will act as a mediator between transformational leadership and dimensions of commitment. That is, transformational leadership would negatively relate to perceived tension, and which in turn decreases affective commitment (Hypothesis 6. a), normative commitment (Hypothesis 6. b) and continuance commitment (Hypothesis 6. c) of employees.

As indicated before, Kelloway et al.'s (2005) "root cause" framework of poor leadership claims that passive leadership behaviors could influence employees' well-being by creating and intensifying workplace stressors. Passive leaders who show ignorance of the needs of their subordinates, refrain from making timely decisions, and interfere with the problems only when they become visible (Kelloway et al., 2005) could cause employees to spend more time and effort for meeting the job requirements. In addition to increased workload, passive leaders could create role conflicts and ambiguities for employees. Such work stressors might result in increased perceived stress, and this stress could spill over the attitudes toward their organization and reduce their commitment. Thus, perceived stress is expected to be a mediator between passive-avoidant leadership and dimensions of commitment. In other words, passive-avoidant leadership will positively relate to perceived tension, which in turn decreases affective (Hypothesis 7. a), normative (Hypothesis 7. b), and continuance commitment (Hypothesis 7. c). The proposed relationships are illustrated in Figure 1.

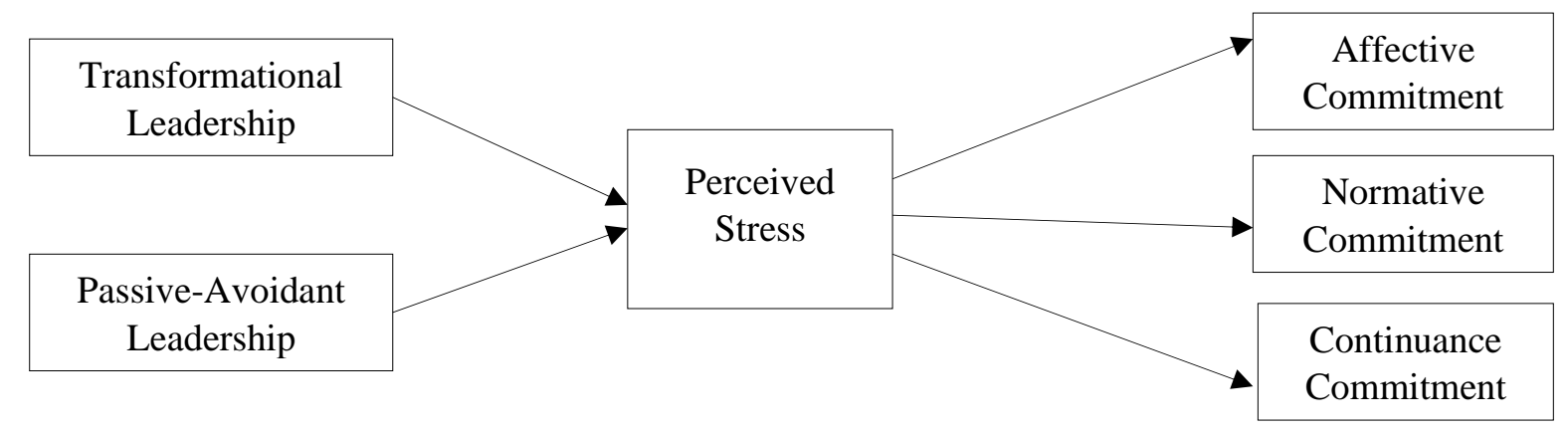

Figure 1. Hypothesized Model 


\section{Method}

\section{Participants}

The study sample includes employees working at regional divisions of a recently privatized organization established to monitor Turkey's electricity distribution services. The company has 21 regional divisions responsible for overseeing the operations of privately-owned electricity distributors. A total of 380 white-collar (42\%) and blue-collar employees (\%58) were working at the regional divisions during the data collection period. The survey package was disseminated to all of the employees, yet 230 questionnaires were returned (response rate $=60 \%$ ). The number of participants turned out to be 228 , after eliminating participants who did not answer the majority of the questionnaire items. The majority of the participants were male (79\%), attributable to the gender-segregated nature of the job. Of those respondents, $49 \%$ were between 26 and 36; 24\% were between 37 and 45; 14\% were between 46 and 55; 7\% were between 18 and 25 age bracket. The distribution of white and blue-collar employees was close to each other (47\% of participants were working in blue-collar positions). The sample was made up of engineers $(25 \%)$, managers ( $8 \%)$, civil servants $(20 \%)$, and workers $(47 \%)$. The majority of the participants were university graduates (95\% including bachelor vocational school, graduate degrees), while only $5 \%$ had high school degrees.

\section{Procedure}

After introducing the study's objectives, the questionnaires were distributed to all employees working at regional divisions. Before the study, informed consent was given to every participant. The participants were ensured of confidentiality. The survey included organizational commitment, leadership, work stress/tension, and some items related to demographics (gender, age, education, job title). The data collection proceeded for six months.

\section{Measures}

Multifactor Leadership Questionnaire (MLQ). The transformational and passive-avoidant leaderships were measured with the MLQ designed by Bass and Avolio (1995). The scale included 45 items measuring nine leadership components, effort, effectiveness, and satisfaction. Among 45, 20 items measure the four sub-dimensions of transformational leadership, eight items assess the two dimensions of transactional leadership, and the remaining eight items assess two dimensions of passive-avoidant leadership. Considering our hypotheses, we used only 28 items to assess transformational and passive leadership styles. Except "charisma" measured with 8-items, all of the transformational leadership dimensions (i.e., intellectual stimulation, inspirational leadership, individual consideration) were measured with 4-items. Passive-avoidant leadership was assessed with two dimensions: management-by-exception (4 items) and laissez-faire leadership (4 items). The response format was a 5-point scale ranging from " $1=$ not at all to $5=$ frequently if not always". Transformational and passive-avoidant leadership scores were derived by summing the items measuring the aforementioned subdimensions (four sub-dimensions for transformational leadership; two sub-dimensions of passive leadership) and dividing by the number of items that make up the sub-dimensions. High scores stand for high levels of transformational and passive leadership. The Cronbach Alpha reliabilities were .95 for transformational leadership, .84 for passive-avoidant leadership. 
Work Tension Scale. Employee's stress and tension were assessed with the 7-item Work Tension Scale developed by House and Rizzo (1972). Respondents indicated their agreement on a 5-point Likert type scale ( $1=$ 'Strongly Disagree' to 5= 'Strongly Agree'). Higher scores indicate higher levels of perceived stress resulting from one's work. The reliability of the worktension scale was found to be .85 .

Organizational Commitment. It was assessed by the three-component model of Meyer and Allen (1991). According to the model, the affective component refers to "an employee's attachment to, identification with, and involvement in the organization" (Meyer \& Allen, 1991; p. 67). The continuance component involves a commitment based on the cost arising from leaving the organization. The last component, the normative component, refers to "employees' feelings of obligation to stay in the organization" (Jaros, 1997, p. 320). All three components of commitment were measured with 25 items, including the revised 18-items by Meyer, Allen, and Smith (1993) and seven items added by Wasti (1999; 2003). More specifically, affective, normative, and continuance commitment were measured with eight, ten, and seven items, respectively. The original scale items (items of Allen and Meyer) and the emic items written by Wasti (1999) were also validated in previous studies (e.g., Wasti, 2003; Tosunoglu, 2014) conducted in Turkey. Therefore, Wasti's (1999) translation was used without any alterations. The respondents indicated the agreements with the scale items using a 5-point multiple choiceresponse format, where scores reflect higher levels of affective, normative, and continuance commitment. The Cronbach Alpha values were .79, .72, and .88 for affective, continuance, and normative commitment, respectively.

\section{Data Analyses}

Following Anderson and Gerbing's (1988) suggestions, initially, confirmatory factor analyses (CFA) were conducted for examining the factorial structures and equivalence of the scales. Several statistics such as Chi-Square, Comparative Fit Index (CFI), and Root Mean Square Error of Approximation (RMSEA) were examined to assess whether the model fits the data. Accordingly, the CFI values of greater than .90 are accepted as an indication of a good fit (Bentler, 1990), whereas RMSEA values of less than .05 are considered as evidence of a good fit, between .05 and .08 a fair fit, and between .08 and .10 a mediocre fit (MacCallum, Browne, \& Sugawara, 1996). After ensuring the factorial equivalence, the internal reliability of the variables was calculated by using Cronbach Alpha statistics. Then, the composite scores for each variable were calculated. Using the composite variables scores, the proposed mediation model was tested with path analysis via AMOS 23 program (Arbuckle, 2014).

\section{Results}

\section{Preliminary Analyses}

Before proceeding to the CFA, the study variables were examined for the outliers, missing values, and normality assumptions. The existence of the univariate and multivariate outliers was checked using z-values, and Mahalanobis Distance statistics, and no outliers were detected. Subsequently, a missing value analysis was conducted. The missing values turned out to be less than 5\% and were in a random pattern; therefore, the missing values were replaced with a mean of respective items. No severe violations of univariate and multivariate normality were detected after conducting Kolmogorov-Smirnov and Mardia's kurtosis tests. 
Two separate CFAs were run for the leadership scale and the other scale items (commitment and trust) separately. The first CFA model comprised two latent constructs with 28 leadership items to test whether the items loaded satisfactorily on transformational and passive leadership constructs. All the 28 items loaded satisfactorily on hypothesized first-order and second-order constructs. The factor loadings were found to be higher than the .50 critical value, except for one item measuring management by exception. The item was excluded from further analysis. After adding the covariance term between the error terms of two items measuring the same construct, the fit indices of the model improved substantially and yielded fair fit to data $\left(\chi^{2}(\mathrm{df}\right.$ $=337)=743.3 ; p<.05, \chi^{2} / \mathrm{df}=2.20, \mathrm{CFI}=.89$, and RMSEA $\left.=.07\right)$. As all the items loaded to the hypothesized construct, the construct validities of the leadership dimensions were assured.

The second CFA model comprised four latent constructs of affective, normative, continuance commitment, and stress factors with eight, eleven, six, and seven items, respectively. After deletion of one item from normative commitment due to insignificant loading and one item from continuance commitment due to low factor loading, the final model yielded a relatively fair fit to data $\left(\chi^{2}(\mathrm{df}=337)=930.67 ; p<.05, \chi^{2} / \mathrm{df}=2.39, \mathrm{CFI}=.88\right.$, and RMSEA = .06). Consistent with the results of Harman's test, the multidimensional factorial structure of the measurement model also indicates that common method variance (CMV) was not a serious concern for the data.

The reliability analysis was conducted based on CFA analysis, and reliabilities were found to be satisfactory for each study variable. After reliability analysis, composite scores for each variable were calculated. For transformational and passive-avoidant leadership, scores in transformational (i.e., intellectual stimulation, inspired motivation, individualized consideration, and charisma) and passive-avoidant leadership (i.e., passive management-byexception and laissez-faire) were averaged. For stress, seven items were averaged to generate a composite score. Then, the correlation analysis was conducted to see the direction and strength of relationships. Table 1 displays the correlation coefficients, descriptive statistics, and Cronbach alpha reliabilities. As seen in Table 1, the correlation analysis revealed a moderate level of association between transformational leadership and stress $(r=-.37 ; p<.05)$ and between passive-avoidant leadership and stress $(r=.39 ; p<.05)$. While the correlations between transformational leadership and all commitment types were significant and in the expected direction, passive-avoidant leadership was only correlated with affective commitment but not with normative and continuance commitment. 
Table 1

Descriptive Statistics of Variables of Interest

\begin{tabular}{|c|c|c|c|c|c|c|c|c|c|c|}
\hline & 1 & 2 & 3 & 4 & 5 & 6 & 7 & 8 & 9 & 10 \\
\hline 1.TL & $1(.95)$ & & & & & & & & & \\
\hline 2.PL & $-.45 * *$ & $1(.84)$ & & & & & & & & \\
\hline 3.Stress & $-.37 * *$ & $.39 * *$ & $1(.85)$ & & & & & & & \\
\hline 4.AC & $.24 * *$ & $-.20 *$ & $-.26 * *$ & $1(.79)$ & & & & & & \\
\hline 5.CC & $.20^{* *}$ & .03 & $-.13^{*}$ & $.56^{* *}$ & $1(.72)$ & & & & & \\
\hline 6.NC & $.21 * *$ & -.11 & $-.24 * *$ & $.71 * *$ & $.70^{* * *}$ & $1(.88)$ & & & & \\
\hline 7.Gender & .08 & .05 & .10 & .05 & -.03 & .077 & 1 & & & \\
\hline 8.Age & -.03 & $.10^{*}$ & -.08 & .08 & .02 & .09 & $.24 * *$ & 1 & & \\
\hline 9. Marital & -.01 & .09 & .01 & .06 & .08 & .06 & $.32 * *$ & $.39^{* * *}$ & 1 & \\
\hline 10.Tenure & -02 & $.11^{*}$ & -.05 & .06 & .01 & .06 & $.22^{* *}$ & $.76^{* * *}$ & $.39^{* *}$ & 1 \\
\hline Mean & 3.65 & 1.93 & 2.33 & 5.22 & 5.28 & 5.23 & - & - & - & - \\
\hline SD & 0.82 & 0.83 & 0.87 & 1.13 & 1.18 & 1.16 & - & - & - & - \\
\hline
\end{tabular}

Note. The numbers in parentheses in the diagonal denote for Cronbach alpha coefficients. TL: Transformational Leadership; PL: Passiveavoidant Leadership, AC: Affective Commitment; CC: Continuance Commitment, NC: Normative Commitment. Gender: $1=$ Women, $2=$ Men, Marital: $1=$ Single, $2=$ Married) $* \mathrm{p}<.05, * * \mathrm{p}<.01$.

\section{Hypotheses Testing}

The hypotheses of the study were tested with the path analysis after ensuring the factorial equivalence of the measurement items in line with the two-step model of Anderson and Gerbing (1988).

The first model tested the direct effect of leadership styles on commitment types. As seen in Table 2, the direct paths from transformational leadership to affective $(\beta=.19, p<.05)$, normative $(\beta=.12, p<.05)$ and continuance commitment $(\beta=.20, p<.05)$ were found to be significant, supporting Hypotheses 1.a, 1.b, and 1.c. However, the paths from passive-avoidant leadership to all three commitment types turned out to be insignificant, rendering Hypotheses 2. a, 2. b, and 2. c unsupported. The mediation hypotheses were tested following the suggestions of MacKinnon, Lockwood, and Williams (2004). Accordingly, the full-mediation model is tested in which transformational and passive-avoidant leadership were assumed to predict employees' stress levels, and then stress levels were linked to affective, normative, and continuance commitment. The examination of the full-mediation model yielded a good fit to data $\left(\chi^{2}(\mathrm{df}=6)=12.63 ; p<.04, \chi^{2} / \mathrm{df}=2.11\right.$, GFI $=.98$, CFI $=.99$, and RMSEA = .07). Transformational and passive-avoidant leadership predicted employees' stress levels significantly in line with Hypotheses 3 and 4. While transformational leadership was negatively associated with stress $(\beta=-.24, p<.05)$, passive-avoidant leadership was positively associated with stress $(\beta=.29, p<.05)$. On the other hand, perceived stress predicted only affective commitment $(\beta=.29, p<.05)$ but not continuance and normative commitment, rendering only Hypothesis 5a. supported.

The mediating effect of perceived stress on the relationship between transformational and passive-avoidant leadership was tested using AMOS bootstrapping by specifying a sample of 2000. It is argued that bootstrapping would provide much statistical power compared to the normal theory approach (MacKinnon et al., 2004). Table 2 also reports confidence intervals (lower and upper level) and the standardized estimates of indirect effects. As seen in Table 2 and Figure 2, the indirect effect of transformational leadership on affective commitment (standardized estimate $=.06, \mathrm{CI}[.02, .13]$ ) and normative commitment (standardized estimate $=.05, \mathrm{CI}[.16, .13])$ via stress yielded significant estimates. Thus, the hypotheses proposing the mediating role of perceived stress on the linkage between transformational leadership-affective 
commitment (Hypothesis 6. a) and between transformational leadership-normative commitment (Hypothesis 6. b) were supported. As for passive-avoidant leadership, the mediating role of perceived stress on the linkage between passive-avoidant leadership and affective commitment (standardized estimate $=-.07$, CI $[-.12,-.13]$ ) and normative commitment (standardized estimate $=-.06$, CI $[-.13,-.02]$ ) were significant. Such findings support Hypothesis 7. a and 7. b.

Table 2

Mediation Analyses: Direct and Indirect Effects and 95\% CIs

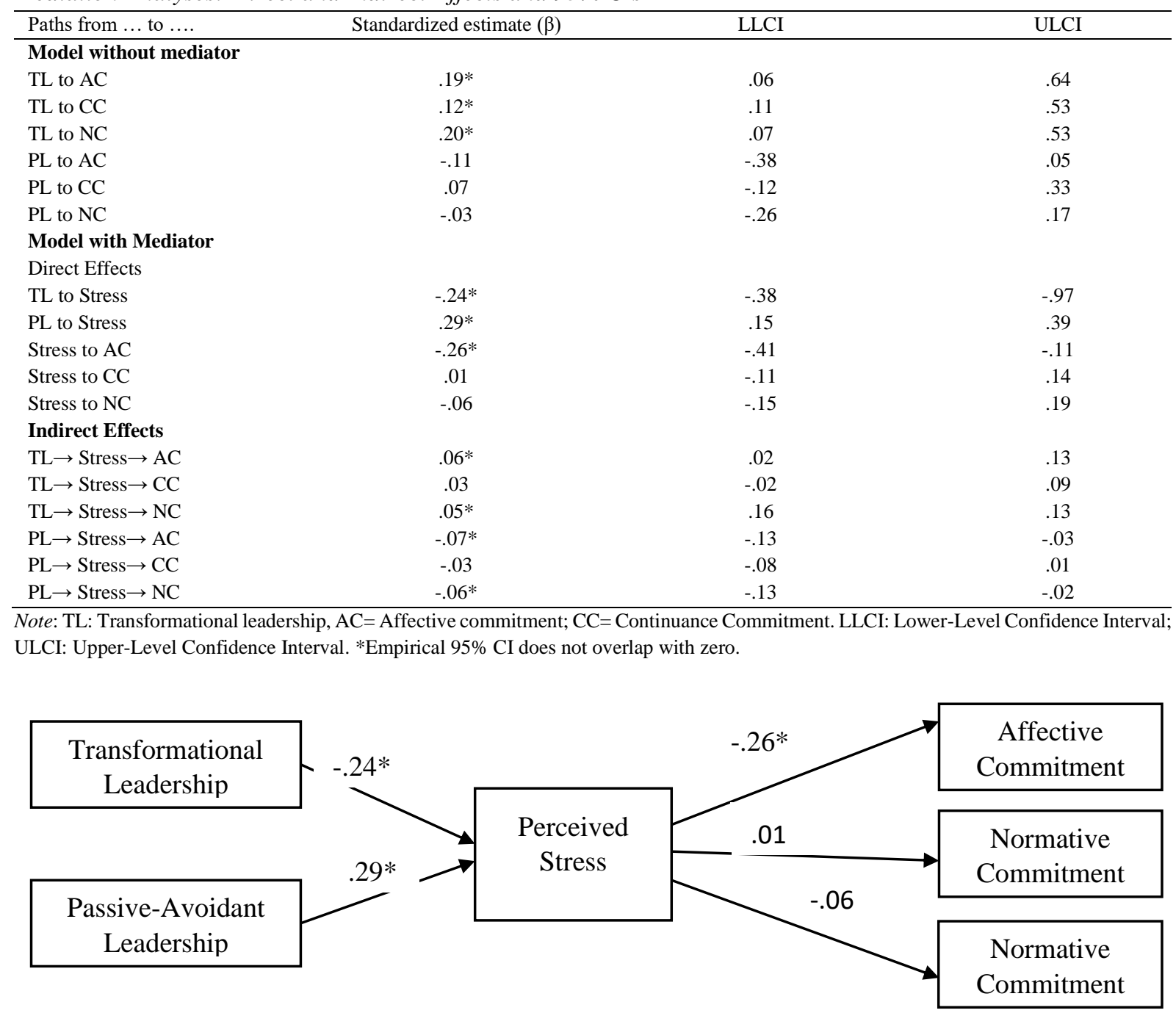

Figure 2. Test of the proposed mediation model

\section{Discussion}

The fundamental proposition of the study is that supervisors' transformational or passive leading styles might influence the stress levels of employees and thereby encourage the motivation of the employees to remain at the organization. The overall results suggest that employees tend to feel less tension and stress and thus become more affectively committed to the organizations when the supervisors exhibit transformational leadership behaviors such as acting as a role model, articulating a vision, and providing individualized support. Both the direct and indirect effects of leadership styles on commitment are discussed in detail below. 


\section{Transformational and Passive-Avoidant Leadership and Perceived Stress: Direct Effects}

The findings of the study revealed that leadership styles predicted the perceived stress and tension of the employees. In particular, while transformational leadership reduced the stress level of the employees, passive-avoidant leadership increased the stress. By collaborating and cooperating with employees on and trying to anticipate and figure out workplace problems in advance, transformational leaders could instill confidence among the subordinates about the fulfillment of work responsibilities and reduce role stressors, thereby alleviating the perceived stress of subordinates. Such finding corroborates the previous studies of Amirkhani and Kazemi (2016) and Nielsen et al. (2008). In line with the premises of COR theory, transformational leadership seems to help employees obtain or maintain needed resources to complete the work by giving timely feedback and instrumental support. It seems to reduce the presence and intensity of work stressors, which ease the employees' stress level.

Passive-avoidant leadership, conversely, was found to intensify employees' stress levels. By not providing the resources needed by subordinates to fulfill their work requirements, passive-avoidant leaders seem to trigger the perception of resource loss, which alleviated the tension felt by the followers. Apart from resource loss, the 'root cause' framework (Kelloway et al., 2005) of poor leadership could explain the linkage between passive-avoidant leadership and stress. This framework proposes that passive leadership behaviors can affect employees' well-being and stress by affecting the nature of the work setting stressors. In particular, passive leaders seem to increase employees' work-related strain when avoidant leaders fail to consider the needs of the subordinates, elude decision making, and only intrude on the problems that arise (Kelloway et al., 2005). By failing to provide the resources and structure needed to complete the work, passive leaders could force subordinates to complete their job duties and responsibilities and do a variety of unnecessary tasks. Due to role ambiguities and conflicts, employees might need to spend time and effort completing their tasks, resulting in amplified workload. Moreover, since passive leaders fail to give sufficient feedback, those neglected employees could do the same task repeatedly or make similar mistakes, which could increase the time needed for task accomplishment. In other words, by not showing effective and active leadership, passive-avoidant leaders seem to increase the perceived stress of their followers.

\section{Direct Effects of Perceived Stress on Commitment}

The study revealed that perceived stress only predicted affective commitment of the employees, but not normative and continuance commitment. Such finding seems to support the assertion of Meyer, Allen, and Smith (1993), which suggests that three components of commitment are "differentially correlated to the variables purported to be antecedents of commitment" (p. 539). Reflecting affective attachment and emotional bond to the organization, the affective commitment was affected by perceived stress more than other dimensions of commitment. Prior studies found the affective commitment to be mostly associated with work experiences, whereas normative and continuance commitment to be associated by perceived obligations and cost of leaving the organizations, respectively (e.g., Meyer, Allen, \& Smith, 1993).

Perceived stress seems to negatively affect the employees' work experiences, which in turn reduces the employees' affective commitment to the organizations. The finding seems to be in line with the premises of the Spill-over effect, which asserts that negative feelings and experiences arising from perceived job stress spillover toward the feelings toward the 
organization, thereby hamper employees' employees' emotional attachment to their organizations.

\section{The Mediating Effects of Perceived Stress}

The current study revealed that perceived stress mediated the relationship between transformational leadership and affective commitment and the relationship between transformational leadership and normative commitment, but not mediated the relationship between transformational leadership and continuance commitment. The mediating effects of perceived stress could be explained with Spillover Effect and COR theory. Transformational leaders likely provide adequate emotional and instrumental support to employees by showing individualized consideration, inspiration, and stimulation. Such kind of support seems to act as an important resource for the completion of the work, which reduces the intensity and presence of work stressors, thereby alleviating the employees' perceived stress. Furthermore, reduction of the stress and resulting positive feelings seem to spill over to attitudes toward the organization and increase employees' psychological attachment toward the organization. Likewise, followers' decreased levels of stress with exposure to transformational leadership practices could indirectly affect employees' normative commitment. As normative commitment refers to the general sense of obligation, when faced with inspiring, encouraging, and stimulating leaders, the followers could feel less stress, thus responding by staying at the organization since such action is regarded as the right and moral thing to do.

The mediating role of perceived stress on the relationships among passive-avoidant leadership and affective and normative commitment yielded support. Hence, passive-avoidant leaders were found as distal predictors of affective and normative commitment via perceived stress. Such findings could be interpreted under premises of root-cause theory, which argues that passive leaders could intensify workplace stressors for followers by enacting passively and showing ignorance to subordinates' needs (Kelloway et al., 2005). The accelerated levels of stress could then lead to eroding positive attitudes toward the organization and detachment from the organization.

Contrary to expectations, the indirect effects of both transformational and passive-avoidant leadership styles on continuance commitment via stress were not supported. This might be explained by the nature of the continuance commitment, which has been previously shown to be more related to increased investment in terms of tenure and employment status (Meyer et al., 1993). Likewise, continuance commitment was argued to be more associated with the sidebets (i.e., input/output ratio) and external factors such as opportunities for alternative employments, rather than leadership practices (Powell \& Meyer, 2004; Yahaya \& Ebraham, 2016).

\section{Limitations and Directions for Future Research}

The first limitation concerns the cross-sectional nature of the study, which limits causal inferences. Thus, further longitudinal data is of great need for a better understanding of the causal relationship between study variables. Additional research is also needed to examine the causal precedence of commitment and stress. Likewise, the second limitation relates to the selfreported data collection. However, this data collection technique could cast doubts about results because employees' ability to analyze their stress level and other study variables may be 
confounded by several unforeseen factors, such as negative affectivity, unemployment levels, and degree of leader-member exchange. Also, relying on self-reporting might have caused a common method variance problem (CMV), which could inflate the magnitude of the observed relationships. Although several remedies (i.e., Harman's test, use of different response formats) were utilized to eliminate and examine the plausible effects of the CMV problem, researchers might gather data from other sources such as supervisors or peers in future studies to rule out CMV problem. For example, employees' commitment to their organization could be assessed by their supervisor.

Even with the limitations, this study hopefully contributes to the extant literature by establishing the role of both constructive and unconstructive forms of leadership on employees' commitment through its effects on perceived stress. Yet, several individuals or organizational factors not considered in this study might have confounded the results. Therefore, future studies are encouraged to address the role of individual and situational variables, such as neuroticism, work stressors (i.e., role conflict, work-family interference) to explain stress and commitment. By treating these variables as moderators, a more comprehensive model explaining the linkage between leadership styles and commitment could be offered. Besides that, we treated stress as an antecedent of commitment; however, we acknowledge the possibility of a reverse relationship between these two variables. Highly committed employees could experience greater stress from workplace stressors or non-ideal leaders (i.e., passive-avoidant or destructive leadership). So, we believe prospective research is required to examine the causal precedence of commitment and stress.

\section{Practical Implications}

The findings revealed that styles of leadership style have considerable effects on employees' stress levels. Transformational leaders seem to reduce employees' stress levels, which in turn positively affects employees' emotional attachment to the organizations. Therefore, improving the leadership skills of managers or administrators could be valuable in creating a less stressful work environment. Organizations might also utilize leadership assessments for the candidates in managerial positions to identify transformational leadership behaviors. Then, the potential management candidates exhibiting the characteristics of a transformational leader could be provided into management trainee programs and interventions to improve the leadership skills. In addition to training, organizations could identify managers or administrators with characteristics peculiar to transformational leaders through sound selection programs. Personality tests or assessment centers could be used for that type of purpose.

However, focusing solely on transformational leadership may not be adequate given the plausible effects of passive leadership on employees. Although the study findings found no relationship between commitment and passive leadership, passive leaders seem to affect employees negatively by increasing the tension and strain. As Che et al. (2017) noted in identifying stressors in work settings, organizations need to focus on destructive leadership behaviors and beware of passive leadership behaviors such as avoiding employee needs or solving problems only when they occur. Although not tested in the study, such avoidant behaviors seem to increase perceived stressors, thus alleviating the employees' stress levels. As in transformational leadership, organizations could use leadership assessment programs or techniques to identify managers who display passive leadership behaviors. 


\section{References}

Aasland, M. S., Skogstad, A., Notelaers, G., Nielsen, M. B., \& Einarsen, S. (2010). The prevalence of destructive leadership behavior. British Journal of Management, 21(2), 438-452. https://doi.org/10.1111/j.1467-8551.2009.00672.x

Allen, N. J., \& Meyer, J. P. (1990). The measurement and antecedents of affective, continuance, and normative commitment to the organization. Journal of Occupational Psychology, 63(1), 1-18. https://doi.org/10.1111/j.20448325.1990.tb00506.x

Amirkhani, A. H., \& Kazemi, M. (2016). Effect of Transformational Leadership on Employee Stress and Fatigue in Payam Noor University. International Business Management, 10, 5475-5480. http://doi: 10.3923/ibm.2016.5475.5480

Anderson, J. C., \& Gerbing, D. W. (1988). Structural equation modeling in practice: A review and recommended a two-step approach. Psychological Bulletin, 103(3), 411-423. http://doi.org/10.1037/0033-2909.103.3.411

Antonakis, J. (2001). The validity of the transformational, transactional, and laissez-faire leadership model as measured by the Multifactor Leadership Questionnaire (MLQ 5X) (Unpublished doctorate dissertation). Walden University, Washington.

Arbuckle, J. L. (2014). Amos (Version 23.0) [Computer Program]. Chicago: IBM SPSS.

Arnold, K. A. (2017). Transformational leadership and employee psychological well-being: A review and directions for future research. Journal of Occupational Health Psychology, 22(3), 381-393. https://doi.org/10.1037/ocp0000062

Aycan, Z., \& Fikret-Pasa, S. (2003). Career choices, job selection criteria, and leadership preferences in a transitional nation: The case of Turkey. Journal of Career Development, 30(2), 129-144. https://doi.org/10.1023/A:1026112127918

Aycan, Z., Kanungo, R., Mendonca, M., Yu, K., Deller, J., Stahl, G., \& Kurshid, A. (2000). Impact of culture on human resource management practices: A 10-country comparison. Applied Psychology: An International Review, 49(1), 192221. https://doi.org/10.1111/1464-0597.00010

Aydogmus, C., Camgoz, S. M., Ergeneli, A., \& Ekmekci, O. T. (2018). Perceptions of transformational leadership and job satisfaction: The roles of personality traits and psychological empowerment. Journal of Management \& Organization, 24(1), 81-107. https://doi.org/10.1017/jmo.2016.59

Bao, Y., Dolan, S. L., \& Tzafrir, S. S. (2012). Value congruence in organizations: Literature review, theoretical perspectives, and future directions. ESADE Business School Research Paper, 239. Retrieved from SSRN: https://ssrn.com/abstract=2154976 or http://dx.doi.org/10.2139/ssrn.2154976

Barling, J., \& Frone, M. R. (2017). If only my leader would just do something! Passive leadership undermines employee well-being through role stressors and psychological resource depletion. Stress and Health, 33(3), 211-222. https://doi.org/10.1002/smi.2697

Bass, B. M., \& Avolio, B. J. (1993). Transformational leadership and organizational culture. Public Administration Quarterly, 17, 112-121. https://www.jstor.org/stable/40862298

Bass, B. M., \& Avolio, B. J. (1995). The Multifactor Leadership Questionnaire. Palo Alto, CA: Mind Garden.

Bass, B. M., \& Avolio, B. J. (1997). Full range leadership development: Manual for the Multifactor Leadership Questionnaire (pp. 43-44). Palo Alto, CA: Mind Garden.

Bentler, P. M. (1990). Comparative fit indexes in structural models. Psychological Bulletin, 107(2), $238-246$. http://dx.doi.org/10.1037/0033-2909.107.2.238

Bono, J. E., \& Judge, T. A. (2003). Self-concordance at work: Toward understanding the motivational effects of transformational leaders. Academy of Management Journal, 46(5), 554-571. https://doi.org/10.5465/30040649.

Boxx, W. R., Odom, R. Y., \& Dunn, M. G. (1991). Organizational values and value congruency and their impact on satisfaction, commitment, and cohesion: An empirical examination within the public sector. Public Personnel Management, 20(2), 195-205. https://doi.org /10.1177/009102609102000207

Burris, E. R., Detert, J. R., \& Chiaburu, D. S. (2008). Quitting before leaving: the mediating effects of psychological attachment and detachment on voice. Journal of Applied Psychology, 93(4), 912-922. http://dx.doi.org/10.1037/00219010.93.4.912

Bycio, P., Hackett, R. D., \& Allen, J. S. (1995). Further assessments of Bass's (1985) conceptualization of transactional and transformational leadership. Journal of Applied Psychology, 80(4), 468-478. http://doi:10.1037/0021-9010.80.4.468

Che, X. X., Zhou, Z. E., Kessler, S. R., \& Spector, P. E. (2017). Stressors beget stressors: The effect of passive leadership on employee health through workload and work-family conflict. Work \& Stress, 31(4), 338-354. http://doi:10.1080/02678373.2017.1317881

Elliot, A. J., \& Devine, P. G. (1994). On the motivational nature of cognitive dissonance: Dissonance as psychological discomfort. Journal of Personality and Social Psychology, 67(3), 382-394. http://doi:10.1037/0022-3514.67.3.382 
Emery, C. R., \& Barker, K. J. (2007). The effect of transactional and transformational leadership styles on the organizational commitment and job satisfaction of customer contact personnel. Journal of Organizational Culture, Communications, and Conflict, 11(1), 77-90.

Harold, C. M., \& Holtz, B. C. (2015). The effects of passive leadership on workplace incivility. Journal of Organizational Behavior, 36(1), 16-38. https://doi.org/10.1002/job.1926

Hinkin, T. R., \& Schriesheim, C. A. (2008). An examination of "nonleadership": From laissez-faire leadership to leader reward omission and punishment omission. Journal of Applied Psychology, 93(6), 1234-1248. http://dx.doi.org/10.1037/a0012875

Hobfoll, S. E. (1989). Conservation of resources: A new attempt at conceptualizing stress. American Psychologist, 44(3), 513-524. http://doi:10.1037/0003-066X.44.3.513

Hofstede, G. (1980). Culture and organizations. International Studies of Management \& Organization, 10(4), 15-41. http://doi.org/10.1080/00208825.1980.11656300

Holtz, B. C., \& Hu, B. (2017). Passive leadership: relationships with trust and justice perceptions. Journal of Managerial Psychology, 32(1), 119-130. http://doi.org/10.1108/JMP-02-2016-0029

Howell, J. M., \& Avolio, B. J. (1993). Transformational leadership, transactional leadership, locus of control, and support for innovation: Key predictors of consolidated-business-unit performance. Journal of Applied Psychology, 78(6), 891902. http://dx.doi.org/10.1037/0021-9010.78.6.891

House, R. J., \& Rizzo, J. R. (1972). Toward the measurement of organizational practices: Scale development and validation. Journal of Applied Psychology, 56(5), 388-396. http://dx.doi.org/10.1037/h0033444

Jamal, M. (1990). Relationship of job stress and Type-A behavior to employees' job satisfaction, organizational commitment, psychosomatic health problems, and turnover motivation. Human Relations, 43(8), 727-738. https://doi.org/10.1177/0018726790 04300802

Jaros, S. J. (1997). An assessment of Meyer and Allen's (1991) three-component model of organizational commitment and turnover intentions. Journal of Vocational Behavior, 51(3), 319-337. https://doi.org/10.1006/jvbe.1995.1553

Judge, T. A., \& Piccolo, R. F. (2004). Transformational and transactional leadership: a meta-analytic test of their relative validity. Journal of Applied Psychology, 89(5), 755-768. https://doi.org/10.1037/0021-9010.89.5.755

Kelloway, E. K., Mullen, J., \& Francis, L. (2006). Divergent effects of transformational and passive leadership on employee safety. Journal of Occupational Health Psychology, 11(1), 76-86. http://dx.doi.org/10.1037/1076-8998.11.1.76

Kelloway, E. K., Sivanathan, N., Francis, L., \& Barling, J. (2005). Poor leadership. In J. Barling, E. K. Kelloway, \& M. R. Frone (Eds.), Handbook of work stress (pp. 89-112). California: Sage Publications, Inc.

Korek, S., Felfe, J., \& Zaepernick-Rothe, U. (2010). Transformational leadership and commitment: A multilevel analysis of group-level influences and mediating processes. European Journal of Work and Organizational Psychology, 19(3), 364387. https://doi.org/10.1080/13594320902996336

Kuhnert, K. W., \& Lewis, P. (1987). Transactional and transformational leadership: A constructive/developmental analysis. Academy of Management Review, 12(4), 648-657.

Liu, J., Siu, O. L., \& Shi, K. (2010). Transformational leadership and employee well-being: The mediating role of trust in the leader and self-efficacy. Applied Psychology, 59(3), 454-479. https://doi.org/10.1111/j.1464-0597.2009.00407.x

Lowe, K. B., Kroeck, K. G., \& Sivasubramaniam, N. (1996). Effectiveness correlates of transformational and transactional leadership: A meta-analytic review of the MLQ literature. The Leadership Quarterly, 7(3), 385-425. https://doi.org/10.1016/S1048-9843(96)90027-2.

MacCallum, R. C., Browne, M. W., \& Sugawara, H. M. (1996). Power analysis and determination of sample size for covariance structure modeling. Psychological Methods, 1(2), 130-149. http://dx.doi.org/10.1037/1082-989X.1.2.130

MacKinnon, D. P., Lockwood, C. M., \& Williams, J. (2004). Confidence limits for the indirect effect: Distribution of the product and resampling methods. Multivariate Behavioral Research,39(1), 99-128. https://doi.org/10.1207/s15327906mbr3901_4

Mathieu, J. E., \& Zajac, D. M. (1990). A review and meta-analysis of the antecedents correlate, and consequences of organizational commitment. Psychological Bulletin, 108(2), 171-194. http://dx.doi.org/10.1037/0033-2909.108.2.171

Meyer, J. P., \& Allen, N. J. (1991). A three-component conceptualization of organizational commitment. Human Resource Management Review, 1(1), 61-89. https://doi.org/10.1016/1053-4822(91)90011-Z

Meyer, J. P., Allen, N. J., \& Smith, C. A. (1993). Commitment to organizations and occupations: Extension and test of a three-component conceptualization. Journal of Applied Psychology, 78(4), 538- -551. http://dx.doi.org/10.1037/00219010.78.4.538

Meyer, J. P., Stanley, D. J., Herscovitch, L., \& Topolnytsky, L. (2002). Affective, continuance, and normative commitment to the organization: A meta-analysis of antecedents, correlates, and consequences. Journal of Vocational Behavior, 61(1), 20-52. https://doi.org/10.1006/jvbe.2001.1842 
Mowday, R. T., Porter, L. W., \& Steers, R. M. (1982). Employee-organization linkage: The psychology of commitment absenteeism, and turnover. Academic Press, New York

Nguni, S., Sleegers, P., \& Denessen, E. (2006). Transformational and transactional leadership effects on teachers' job satisfaction, organizational commitment, and organizational citizenship behavior in primary schools: The Tanzanian case. School Effectiveness and School Improvement, 17(2), 145-177.

Nielsen, K., Randall, R., Yarker, J., \& Brenner, S. O. (2008). The effects of transformational leadership on followers' perceived work characteristics and psychological well-being: A longitudinal study. Work \& Stress, 22(1), 16-32. https://doi.org/ 10.1080/ 02678370801979430

Powell, D. M., \& Meyer, J. P. (2004). Side-bet theory and the three-component model of organizational commitment. Journal of Vocational Behavior, 65(1), 157-177.

Robinson, S. L. (1996). Trust and breach of the psychological contract. Administrative Science Quarterly, 41(4), 574-599. http://doi.org/10.2307/2393868

Rousseau, D. M. (1989). Psychological and implied contracts in organizations. Employee Responsibilities and Rights Journal, 2(2), 121-139. https://doi.org/10.1007/BF01384942

Schyns, B., \& Schilling, J. (2013). How bad are the effects of bad leaders? A meta-analysis of destructive leadership and its outcomes. The Leadership Quarterly, 24(1), 138-158. https://doi.org/10.1016/j.leaqua.2012.09.001

Skogstad, A., Einarsen, S., Torsheim, T., Aasland, M. S., \& Hetland, H. (2007). The destructiveness of laissez-faire leadership behavior. Journal of Occupational Health Psychology, 12(1), 80-92. http://doi:10.1037/1076-8998.12.1.80

Tosunoglu, H. (2014). The mediating role of trust in organizations on the relationship between perceptions of leadership style and organizational commitment: Case Study (Unpublished master's thesis). Hacettepe University: Ankara.

Tosunoglu, H., \& Ekmekci, O. (2016). Laissez-Faire leaders and organizations: How does laissez-faire leader erode the trust in organizations? Journal of Economics Finance and Accounting, 3(1), 89-99. http://doi:10.17261/Pressacademia.2016116538

Tepper, B. J. (2000). Consequences of abusive supervision. Academy of Management Journal, 43(2), 178-190. https://doi.org/10.5465/1556375

Walumbwa, F. O., Orwa, B., Wang, P., \& Lawler, J. J. (2005). Transformational leadership, organizational commitment, and job satisfaction: A comparative study of Kenyan and US financial firms. Human Resource Development Quarterly, 16(2), 235-256. https://doi.org/10.1002/hrdq.1135

Wasti, S. A. (1999). Organizational commitment in a collectivist culture: The case of Turkey (Unpublished doctoral dissertation). the University of Illinois at Urbana-Champaign, USA.

Wasti, S. A. (2003). Organizational commitment, turnover intentions, and the influence of cultural values. Journal of Occupational and Organizational Psychology, 76(3), 303-321. https://doi.org/10.1348/096317903769647193.

Wu, J., Hom, P., Tetrick, L., Shore, L., Jia, L., Li, C., \& Song, L. (2006). The norm of reciprocity: Scale development and validation in the Chinese context. Management and Organization Review, 2(3), 377-402. https://doi.org/10.1111/j.17408784.2006.00047.x

Yahaya, R., \& Ebrahim, F. (2016). Leadership styles and organizational commitment: a literature review. Journal of Management Development, 35(2), 190-216. https://doi.org/ 10.1108/JMD-01-2015-0004

\section{Acknowledgements}

This research was presented at the International Congress of Psychology, Prague, 2021 as an oral presentation with the same title.

\section{Disclosure Statement}

No potential conflict of interest was reported by the authors.

\section{Funding Acknowledgements}

Not applicable.

\section{Open Access}

The International Journal of Organizational Leadership publishes open access articles under the terms of the Creative Commons Attribution (CC BY) License, which permits use, distribution, and reproduction in any medium, provided the original work is properly cited. 